\title{
Traumatic Brain Injury Stimulates Neural Stem Cell Proliferation via Mammalian Target of Rapamycin Signaling Pathway Activation
}

\author{
(1) Xiaoting Wang, ${ }^{1,2,3}$ Pich Seekaew, ${ }^{1,2,3}$ ํ) Xiang Gao, ${ }^{1,2,3}$ and Jinhui Chen ${ }^{1,2,3}$
}

\section{DOI:http://dx.doi.org/10.1523/ENEURO.0162-16.2016}

\begin{abstract}
${ }^{1}$ Spinal Cord and Brain Injury Research Group, Indiana University, Indianapolis, IN 46202, ${ }^{2}$ Stark Neuroscience Research Institute, Indiana University, Indianapolis, IN 46202, and ${ }^{3}$ Department of Neurological Surgery, Indiana University, Indianapolis, IN 46202
\end{abstract}

\begin{abstract}
Neural stem cells in the adult brain possess the ability to remain quiescent until needed in tissue homeostasis or repair. It was previously shown that traumatic brain injury (TBI) stimulated neural stem cell (NSC) proliferation in the adult hippocampus, indicating an innate repair mechanism, but it is unknown how TBI promotes NSC proliferation. In the present study, we observed dramatic activation of mammalian target of rapamycin complex 1 (mTORC1) in the hippocampus of mice with TBI from controlled cortical impact (CCl). The peak of mTORC1 activation in the hippocampal subgranular zone, where NSCs reside, is 24-48 h after trauma, correlating with the peak of TBI-enhanced NSC proliferation. By use of a Nestin-GFP transgenic mouse, in which GFP is ectopically expressed in the NSCs, we found that TBI activated mTORC1 in NSCs. With 5-bromo-2'-deoxyuridine labeling, we observed that TBI increased mTORC1 activation in proliferating NSCs. Furthermore, administration of rapamycin abolished TBI-promoted NSC proliferation. Taken together, these data indicate that mTORC1 activation is required for NSC proliferation postinjury, and thus might serve as a therapeutic target for interventions to augment neurogenesis for brain repair after TBI.
\end{abstract}

Key words: mammalian target of rapamycin; neural stem/progenitor cells; proliferation; quiescence; traumatic brain injury

\section{Significance Statement}

Traumatic brain injury (TBI)-induced cell death compromises learning and memory functions in survivors by disconnecting neurocircuitries in the hippocampus, prompting an urgent need for repair strategies. Innate repair machinery driven by endogenous neural stem cells (NSCs) responds to injury but does not effect full recovery. The mechanisms of injury-induced NSC activation are elusive, further impeding possible interventions for intrinsic restoration. This study demonstrates that mTORC1 signal is activated in NSCs after trauma, and further inhibition on the mTORC1 pathway diminished the effects of injury on NSC proliferation. The results suggest that mTORC1 activation mediates TBI-enhanced NSC proliferation, providing a clinically relevant potential therapeutic target for modulation of postinjury NSC activity.

\section{Introduction}

Traumatic brain injury (TBI), as a public health issue in the United States, causes 2.5 million hospital visits each

Received June 15, 2016; accepted September 23, 2016; First published October 20, 2016.

The authors declare no conflict of interest.

Contribution Statement: X.W., collection and/or assembly of data, data year (Faul et al., 2010), and 52,000 patients die of severe injuries. In survivors, both physical and neurobehavioral disabilities frequently occur (Salmond and Sahakian, 
2005), as well as an increased susceptibility to neurodegenerative diseases such as Alzheimer's disease and Parkinson's disease (Sivanandam and Thakur, 2012; Marras et al., 2014). The hippocampus is one of the brain regions most vulnerable to cell death (Colicos et al., 1996, Hicks et al., 1996; Sato et al., 2001; Hall et al., 2005), primarily acute necrotic immature neuron death in the hippocampal dentate gyrus (HDG) after trauma (Gao et al., 2008; Zhou et al., 2012). This damage results in learning and memory dysfunctions as the most common sequelae of TBI (Salmond and Sahakian, 2005; Perry et al., 2015). However, effective drugs approved by the Food and Drug Administration against cell death after TBI are unavailable. There is an urgent need for an alternative approach to neuronal replacement in the damaged hippocampus to promote cognitive functional recovery.

Adult neural stem/progenitor cells (NSCs) have been widely discovered in birds, rodents, primates, and human beings (Reynolds and Weiss, 1992; Eriksson et al., 1998; Kornack and Rakic, 1999; Nottebohm, 2002). The subgranular zone (SGZ) in the hippocampus is one of the most important niches for adult NSCs to support neurogenesis through a lifetime (Cameron and McKay, 2001; van Praag et al., 2002), contributing to learning and memory capacity (Shors et al., 2001; Kitamura et al., 2009; Akers et al., 2014; Christian et al., 2014). In both rodent models and human beings, NSC proliferation is promoted after TBI in the adult hippocampus (Dash et al., 2001; Kernie et al., 2001; Braun et al., 2002; Chirumamilla et al., 2002; Rice et al., 2003; Ramaswamy et al., 2005; Sun et al., 2005; Gao et al., 2009; Zheng et al., 2013), indicating an innate repair response of NSCs to initial injury, shown as immature neuron loss compensated in the dentate gyrus, as well as increased postinjury mature neurons in some cases (Braun et al., 2002; Sun et al., 2005, 2007; Gao and Chen, 2013; Wang et al., 2016). Moreover, neurogenesis levels after trauma correlate with injury severity (Wang et al., 2016). Functionally, neurons born after injury integrate into preexisting neurocircuitries (Emery et al., 2005; Sun et al., 2007; Villasana et al., 2015) and are responsible for spontaneous recovery (Schmidt et al., 1999; Blaiss et al., 2011; Sun et al., 2015). However, this innate repair cannot always completely compensate for cell loss, resulting in retention of permanent functional deficits in numerous TBI survivors (Prigatano, 1987; Cicerone et al., 2005). After treatment with some neurogenic agents, enhanced endogenous neurogenesis and functional improvements have been positively correlated in

This work was supported by funding from the Indiana Spinal Cord and Brain Injury Research Grants, the Ralph W. and Grace M. Showalter Research Award, and Indiana University Biological Research Grant.

Correspondence should be addressed to Jinhui Chen, MD, PhD, Department of Neurological Surgery and Stark Neuroscience Research Institute, Indiana University, Neurosciences Research Building, 320 W 15th Street, Indianapolis, IN 46202. E-mail: chen204@iupui.edu.

DOI:http://dx.doi.org/10.1523/ENEURO.0162-16.2016

Copyright (C) 2016 Wang et al.

This is an open-access article distributed under the terms of the Creative Commons Attribution 4.0 International, which permits unrestricted use, distribution and reproduction in any medium provided that the original work is properly attributed. injured mice (Lu et al., 2003; Kleindienst et al., 2005; Lu et al., 2005; Wu et al., 2008). Taken together, these data suggest it is feasible to fully repair TBI-induced neuronal loss and restore cognitive functions by enhancing endogenous NSC-mediated neurogenesis.

NSC activity is regulated by various extracellular signals (Lie et al., 2005; Sierra et al., 2015), making it difficult to tease out the mediators of TBI-enhanced NSC proliferation. In the present study, we instead investigated the intracellular pathway to shed light on the mechanisms activating the proliferation program in NSCs after trauma. The mammalian target of rapamycin (mTOR) pathway, especially mTOR complex 1 (mTORC1), is important for coordinating extracellular signals and regulating cell proliferation (Laplante and Sabatini, 2012). It is required for maintaining the neural progenitor pool in adult and aging rodents (Paliouras et al., 2012). Additionally, activation of mTORC1 in aging mice rescued the decline of NSC proliferation and neurogenesis in the hippocampus (Romine et al., 2015). Sustained activation of mTORC1 in embryonic and neonatal NSCs leads to an imbalance of proliferation and differentiation (Magri et al., 2011; Hartman et al., 2013). Collectively, mTORC1 plays crucial roles in NSC activity modulation. After TBI, mTORC1 was activated in neurons, microglia, and astrocytes at several time points (Chen et al., 2007; Park et al., 2012). In our study, we examined mTORC1 activation in NSCs within an extended time scale up to 1 week after injury in a controlled cortical impact $(\mathrm{CCl})$ model in mice. Our results indicate that mTORC1 activation in the hippocampus lasts up to $72 \mathrm{~h}$ after injury, whereas mTORC1 activation in NSCs mainly occurs $24-48 \mathrm{~h}$ after trauma. Furthermore, mTORC1 inhibition eliminated TBI-enhanced NSC proliferation in the hippocampus, demonstrating that mTORC1 signaling is required for NSC proliferation after trauma.

\section{Method and Materials}

\section{Animal care}

Male C57 BL/6 mice (The Jackson Laboratory, Bar Harbor, ME) were housed in a 12/12-h light/dark cycle environment. Access to food and water was provided ad libitum. Nestin-enhanced green fluorescent protein (EGFP) mice were kept in the same environment and were a gift from Dr. G. Enikolopov at Cold Spring Harbor Laboratories (Cold Spring Harbor, NY) as previously described (Mignone et al., 2004). All operations were performed according to protocols approved by the Indiana University Animal Care and Use Committee.

\section{CCI traumatic brain injury}

Nine-week-old male mice $(n=62)$ were subjected to $\mathrm{CCl}$ injury or sham surgery. Briefly, a solution of $2.5 \%$ tribromoethanol (Avertin, Sigma-Aldrich, St. Louis, MO) was used to anesthetize the mice. The mice were fixed in a stereotaxic frame (Kopf Instruments, Tujunga, CA), and craniotomy proceeded under sterile conditions. The skin was cut and retracted, and a 4-mm craniotomy was conducted midway between the bregma and lambda sutures and laterally halfway between the central suture and the temporalis muscle. The skullcap was removed carefully 
with intact dura left below. Before injury, the tip of the electromagnetic impactor was adjusted and kept perpendicular to the exposed cortical surface. In the experiments, injury was set at velocity of $3.0 \mathrm{~m} / \mathrm{s}$ and deformation at $1.0 \mathrm{~mm}$ by controlling the electromagnetic impactor. The injury site was permitted to dry before the wound was sutured. A heating pad was used during the whole surgery and recovery period to maintain the animals' core body temperature at $36-37^{\circ} \mathrm{C}$.

\section{Drug administration}

To assess whether mTORC1 inhibition impairs TBIenhanced NSC proliferation, mice were subjected to sham surgery or $\mathrm{CCl}$ injury as described above. Rapamycin (10 mg/kg; LC Laboratories, Woburn, MA) was dissolved in a solution of $5 \%$ PEG $400 / 4 \%$ ethanol and $5 \%$ Tween 80 and administered i.p. 12, 24, 36, and $44 \mathrm{~h}$ after TBI (Fig. 4A). 5-Bromo-2' -deoxyuridine (BrdU; 100 mg/kg in saline; Sigma-Aldrich) was injected i.p. immediately after the final dose of rapamycin (Fig. 4A).

\section{Tissue processing}

To assess the mTORC1 activation time course, mice were sacrificed $4,24,48$, and $72 \mathrm{~h}$ and 1 week after $\mathrm{CCl}$ or after sham surgery. To quantify mTORC1 activation in NSCs and proliferating NSCs after TBI, mice were perfused at 24 or $48 \mathrm{~h}$ after trauma. To evaluate mTORC1 inhibition effects on TBI-enhanced NSC proliferation, mice were sacrificed $48 \mathrm{~h}$ after initial injury and the treatment described above (Fig. 4A). Briefly, the mice were anesthetized deeply and perfused with cold saline transcardially, followed by fixation with $4 \%$ paraformaldehyde (PFA) in PBS. Brain tissues were then collected and postfixed overnight with PFA in $4^{\circ} \mathrm{C}$, followed by cryoprotection in $30 \%$ sucrose for $48 \mathrm{~h}$. Serial coronal sections were cut at 30- $\mu \mathrm{m}$ thickness using a cryostat (LeicaCM 1950; Leica, Buffalo Grove, IL) and preserved at $-20^{\circ} \mathrm{C}$. The sections were processed for immunohistochemical analysis.

\section{Immunohistochemistry}

First, free-floating sections were washed in PBS three times, followed by incubation in blocking buffer $(0.1 \%$ Triton $\mathrm{X}-100,1 \%$ bovine serum albumin, $5 \%$ normal goat serum in PBS) for $1 \mathrm{~h}$. Then sections were incubated with primary antibody overnight at $4^{\circ} \mathrm{C}$, washed for three times in PBS, and then incubated with secondary antibody for 2 h at $4^{\circ} \mathrm{C}$. After $4^{\prime}, 6$-diamidino-2-phenylindole (DAPI) treatment for 2 min, sections were washed again with PBS three times and mounted with Fluoromount-G (SouthernBiotech, Birmingham, AL). For BrdU incorporation, sections were treated before standard blocking protocol as follows: incubation with $2 \mathrm{~N} \mathrm{HCl}$ was performed at room temperature for $1 \mathrm{~h}$, followed by soak in $0.1 \mathrm{M}(\mathrm{pH} 8.4)$ borate buffer for $10 \mathrm{~min}$. After three washes in PBS, sections were processed according to standard protocol in blocking solution. The primary antibodies and their final concentrations used in the experiments were as follows: anti-BrdU (1:200, rat; AbD Serotec, Raleigh, NC), anti-pS6 (1:200, rabbit; Cell Signaling Technology, Danvers, MA), anti-GFP (1:1000, chicken; Abcam, Cambridge, MA), and
anti-Sox2 (1:1000, goat; R\&D Systems, Minneapolis, MN). Secondary antibodies were from Jackson ImmunoResearch Laboratories (West Grove, PA) and applied in a 1:1000 dilution.

\section{Immunoblotting}

To assess mTORC1 activation in the whole hippocampus, mice were sacrificed at $4,24,48$, and $72 \mathrm{~h}$ and 1 week after $\mathrm{CCl}$ or after sham surgery. The ipsilateral hippocampi were collected, homogenized with ice-cold Triton lysis buffer (1\% Triton X-100, 20 mM Tris-HCL, 150 $\mathrm{mm} \mathrm{NaCl}, 5 \mathrm{~mm}$ EGTA, $10 \mathrm{~mm}$ EDTA, and protease inhibitor cocktail [Roche, Basel, Switzerland]), and centrifuged for $30 \mathrm{~min}$ at $14,000 \mathrm{rpm}, 4^{\circ} \mathrm{C}$. Protein concentration was determined by a modified Lowry assay (Bio-Rad, Hercules, CA). The same amount of protein in each sample was loaded and run on SDS/PAGE. After electrotransfer to nitrocellulose membranes at $30 \mathrm{~V}$ overnight at $4^{\circ} \mathrm{C}$, the membrane was incubated in PBS with $5 \%$ nonfat milk at room temperature for $1 \mathrm{~h}$ and probed with antibodies against S6 (1:1000, rabbit, Cell Signaling Technology), $\beta$-actin (1:000, mouse, Abcam), and pS6 (1:200, rabbit, Cell Signaling Technology) overnight at $4^{\circ} \mathrm{C}$. Secondary antibodies were used at a dilution of 1:5000. The membrane was washed three times and rinsed in TBST. Finally, proteins were detected with ECL substrates (BioRad), and images were acquired using normal image scanning methods for colorimetric detection.

\section{Cell counting}

Brain sections were simultaneously processed for immunohistochemistry. An inverted fluorescent microscope system (Axiovert 200M, Zeiss, Jena, Germany) was used to analyze the sections. Series of every sixth section (30 $\mu \mathrm{m}$ thickness, $180 \mu \mathrm{m}$ apart, 12-16 sections in each animal) from covered whole hippocampus were analyzed in a double-blind fashion. Double-positive cells were counted under the microscope with a $40 \times$ objective through the whole series. We used one marker as an indicator; when a positive cell showed in the field, we switched to the channel matching second marker signal. If the target cell also had been labeled, we counted it as a double-positive cell. Triple-positive cells were similarly counted under the microscope through the whole series. We used one marker as an indicator; when a positive cell showed in the field, we switched to the channel matching second marker signal. If the target cell also had been labeled, we again switched to the channel matching third marker signal. Then if the target cell again had been labeled, we counted it as a triple-positive cell.

In all experiments, double- and triple-positive cells were quantified in a double-blind fashion using a profile count method. Briefly, every single colabeled cell (even partial cells at the borders of sections) was counted in multiplanes throughout the region of interest in the $30-\mu \mathrm{m}$ section. Contours of granule cell layer (GCL) were created in Zeiss software (AxioVision v4.8) to measure the volume of GCL. The cell density was calculated by dividing total cell number by the GCL volume, thus expressed as average number $/ \mathrm{mm}^{3}$. 
Table 1. Statistical analysis.

\begin{tabular}{llcl}
\hline Line & Data structure & Type of test & Power \\
a & Normal distribution One-way ANOVA & 0.896 \\
b & Normal distribution One-way ANOVA & 0.941 \\
c & Normal distribution One-way ANOVA & 1.000 \\
d & Normal distribution One-way ANOVA & 1.000 \\
e & Normal distribution One-way ANOVA & 0.999 \\
f & Normal distribution One-way ANOVA & 0.889 \\
g & Normal distribution One-way ANOVA & 0.986 \\
h & Normal distribution One-way ANOVA & 0.997 \\
i & Normal distribution Two-way ANOVA & 0.988 for injury \\
& & 0.732 for treatment \\
& & 0.478 for interaction
\end{tabular}

\section{Microscopy}

The inverted fluorescent microscope (Zeiss Axiovert 200M) used for cell counting and image capture was combined with an ApoTome structured-illumination attachment (Zeiss). A digital camera (Zeiss Axio Cam MRc5) interfaced with the microscope was controlled by a computer. Representative images were captured and stacked as a cut view image in software (AxioVision v4.8). The images were assembled and labeled in Photoshop 7.0 (Adobe Systems, San Jose, CA).

\section{Statistical analysis}

Quantification of target cells is shown as average \pm SD. Data were analyzed via appropriate type of ANOVA followed by Fisher's least significant difference test. Superscript letters listed with $p$-values correspond to the statistical tests shown in Table 1. Statistical analysis was done using SPSS software (IBM, Armonk, NY). Significance was set at $p<0.05$.

\section{Results}

\section{mTORC1 signaling activation in the whole hippocampus after TBI}

NSCs have long been reported to respond to brain injuries, including stroke, seizure, and TBI (Parent et al., 1997, 2002; Dash et al., 2001; Kernie et al., 2001; Yagita et al., 2001; Braun et al., 2002; Chirumamilla et al., 2002; Rice et al., 2003; Ramaswamy et al., 2005; Sun et al., 2005; Yamashita et al., 2006; Gao et al., 2009; Zheng et al., 2013). After TBI, enhanced NSC proliferation in the hippocampus has been observed regardless of injury model and animal model (Dash et al., 2001; Kernie et al., 2001; Braun et al., 2002; Chirumamilla et al., 2002; Rice et al., 2003; Ramaswamy et al., 2005; Sun et al., 2005; Gao et al., 2009; Zheng et al., 2013). It was further demonstrated that quiescent NSCs are the subgroup mainly activated by TBI (Gao et al., 2009). However, the molecular mechanism underlying the phenomenon remains elusive, impeding development of interventions aimed at promoting neurogenesis by further enhancing NSC proliferation after trauma. The mTOR signaling pathway, especially mTORC 1 , is known to be involved in NSC activity regulation in embryonic (Magri et al., 2011), neonatal (Hartman et al., 2013), adult (Paliouras et al., 2012), and aging (Paliouras et al., 2012; Romine et al., 2015) rodents, and its activation has also been reported after TBI in the hippocampus (Chen et al., 2007; Park et al., 2012), so we proposed that mTORC1 signaling mediates TBIenhanced NSC proliferation.

To demonstrate this hypothesis, we induced moderate $\mathrm{TBI}$ in adult mice by a $\mathrm{CCl}$ injury model and evaluated mTORC1 signal activation in the whole hippocampus at different time points postinjury. Adult mice were sacrificed $4,24,48$, and $72 \mathrm{~h}$ and 1 week after $\mathrm{CCl}$ or after sham surgery, and ipsilateral hippocampi were subjected to immunoblotting. We evaluated the total amount and phosphorylated form of ribosomal protein S6 (a widely used marker for mTORC1 activation; Laplante and Sabatini, 2012; Fig. 1A). After trauma, total S6 was elevated rapidly $4 \mathrm{~h}$ postinjury $\left(F_{(5,12)}=5.108, p=0.017^{\mathrm{a}}\right.$; Fig. $\left.1 B\right)$, reached a peak at $24 \mathrm{~h}\left(F_{(5,12)}=5.108, p=0.001^{\mathrm{a}}\right.$; Fig. $1 B)$, stayed at high levels at $48 \mathrm{~h}\left(F_{(5,12)}=5.108, p=\right.$ $0.012^{\mathrm{a}}$; Fig. $\left.1 B\right)$ and $72 \mathrm{~h}\left(F_{(5,12)}=5.108, p=0.043^{\mathrm{a}}\right.$; Fig. $1 B$ ), and returned back to normal level by 1 week after injury $\left(F_{(5,12)}=5.108, p=0.230^{\mathrm{a}}\right.$; Fig. $\left.1 B\right)$. Meanwhile, the phosphorylation level (pS6) was dramatically increased at $4 \mathrm{~h}\left(F_{(5,12)}=6.000, p=0.003^{\text {b}}\right.$; Fig. $\left.1 B\right)$, further elevated at $24 \mathrm{~h}\left(F_{(5,12)}=6.000, p=0.001^{\mathrm{b}}\right.$; Fig. $\left.1 B\right)$, stayed at high levels at $48 \mathrm{~h}\left(F_{(5,12)}=6.000, p=0.013^{\mathrm{b}}\right.$; Fig. $\left.1 B\right)$, remained slightly higher than sham level at $72 \mathrm{~h}\left(F_{(5,12)}=\right.$ $6.000, p=0.091^{\text {b}}$; Fig. $\left.1 B\right)$, and returned comparable to baseline by 1 week $\left(F_{(5,12)}=6.000, p=0.537^{\mathrm{b}}\right.$; Fig. $\left.1 B\right)$. Together, the data suggest that the mTORC1 signal was activated in the hippocampus mainly at 4,24 , and $48 \mathrm{~h}$ after TBI.

\section{mTORC1 signaling activation in the HDG after TBI}

To assess temporal-spatial mTORC1 activation in the HDG, adult mice were sacrificed 4, 24, 48, and $72 \mathrm{~h}$ and 1 week after $\mathrm{CCl}$ or sham surgery. The epicenter section from each animal was processed for immunostaining with antibody against pS6. In sham animals, a limited number of pS6-positive cells were mainly observed in the GCL and few in the hilus, indicating a baseline of mTORC1 activity in the HDG (Fig. 1C). After TBI, we observed a wave of mTORC1 activation in the HDG starting no later than $4 \mathrm{~h}$, maintaining a high level of activation at least until $72 \mathrm{~h}$, and returning to sham level by 1 week postinjury (Fig. 1E, G, I, K, M).

Meanwhile, mTORC1 activation showed different patterns regarding signal location in subregions in the HDG at different time points. At $4 \mathrm{~h}$ after TBI, increased pS6positive cells were predominantly restricted to the GCL (Fig. 1E), indicating a rapid response in granule neurons to the initial insult. At $24 \mathrm{~h}$ after trauma, the pS6-positive cells not only further accumulated in the GCL, but also vastly spread to the molecular layer (ML) and hilus (Fig. $1 G)$. At $48 \mathrm{~h}$ after $\mathrm{CCl}$, the pS6 signal reached a peak, and positive cells were mainly observed in the $M L$ and hilus but few in the GCL (Fig. 1/), implying strong mTORC1 activation in reactive glia, especially reactive microglia, at this time point according to our unpublished data. At $72 \mathrm{~h}$ after trauma, mTORC1 activation started decreasing, and the remaining positive cells were mostly in the ML (Fig. $1 K)$, largely attributable to reactive astrocytes based on our unpublished data. By 1 week after TBI, the pS6 signal 
A

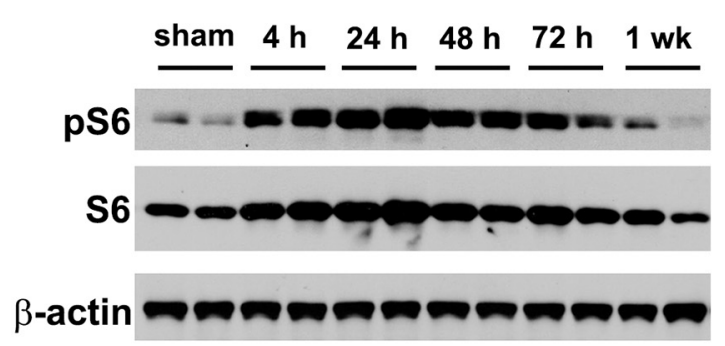

B

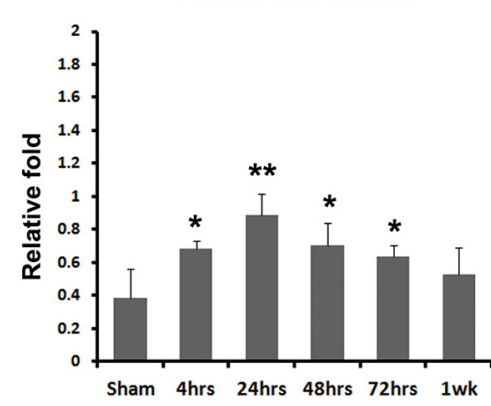

pS6/S6

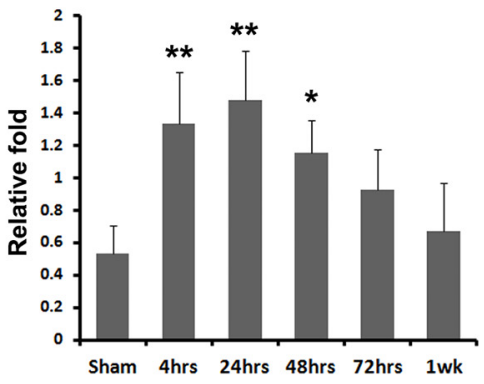

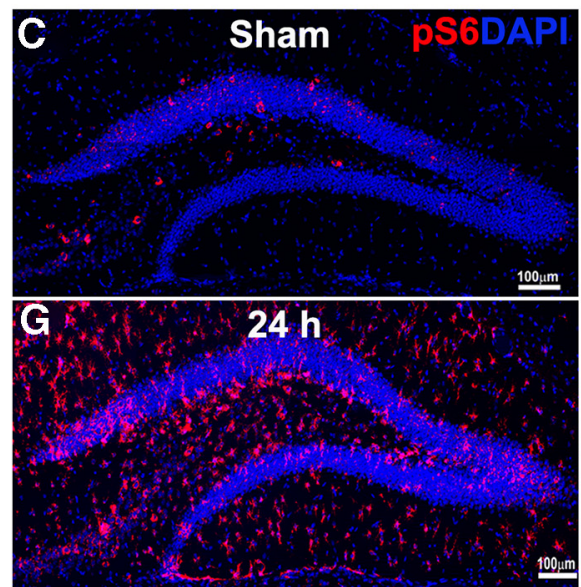
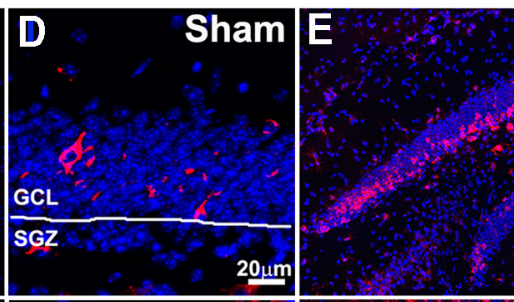

$4 \mathrm{~h}$
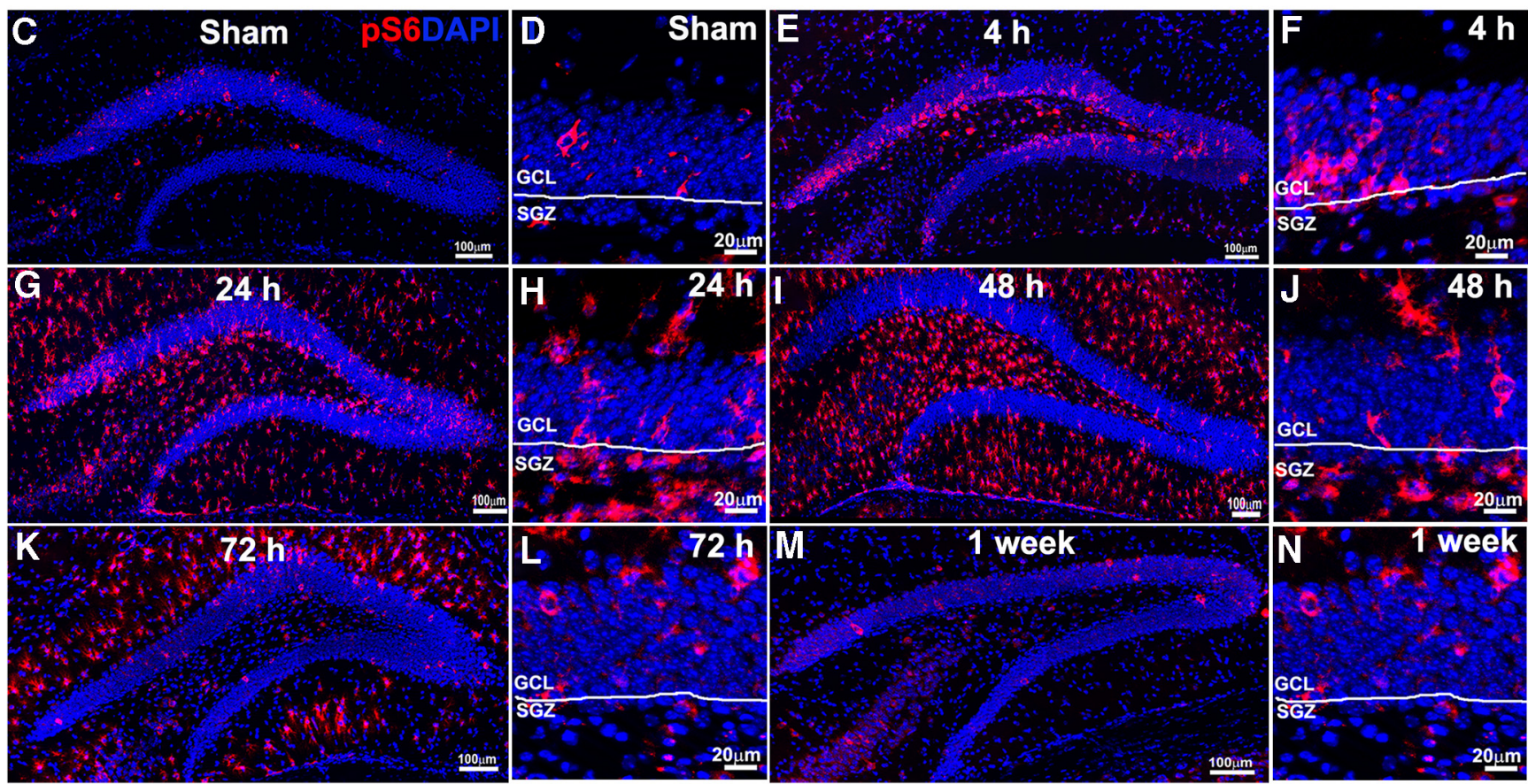

Figure 1. TBI activates mTORC1 signaling in the hippocampus. Mice received a moderate $\mathrm{CCl}$ at the age of 9 weeks and were sacrificed at $4,24,48$, and $72 \mathrm{~h}$ and 1 week after injury as well as after sham injury ( $n=3$ for each group). $\boldsymbol{A}$, Immunoblotting with antibodies against $\mathrm{pS} 6, \mathrm{~S} 6$, and $\beta$-actin shows $\mathrm{mTORC} 1$ signaling activation in the hippocampus. $\boldsymbol{B}$, Quantification of blots shown in $\boldsymbol{A}(* p<0.05, * * p<0.01)$. $\boldsymbol{C}-\mathbf{N}$, Immunostaining with antibody against pS6 (red) shows mTORC1 signaling activation in the HDG after sham surgery $(\boldsymbol{C})$ and $4 \mathrm{~h}(\boldsymbol{E}), 24 \mathrm{~h}(\boldsymbol{G}), 48 \mathrm{~h}(\boldsymbol{I}), 72 \mathrm{~h}(\boldsymbol{K})$, and 1 week $(\boldsymbol{M})$ after $\mathrm{CCl}$, and in the SGZ at corresponding time points $(\boldsymbol{D}, \boldsymbol{F}, \boldsymbol{H}, \boldsymbol{J}, \boldsymbol{L}, \boldsymbol{N})$, respectively. DAPI staining shows the structure of HDG.

was back to sham level and again showed sporadic activation mainly in the GCL (Fig. 1M). Collectively, we detected a time-dependent and location-shifted mTORC1 activation pattern in the HDG after TBI, indicating mTORC1 involvement in various responses to $\mathrm{CCl}$ in multiple cell types.

\section{Time course of mTORC1 signaling activation in the SGZ after TBI}

To further assess whether mTORC1 is activated in the NSCs after TBI, we focused on pS6 signal in the SGZ, where adult NSCs locate in the hippocampus (Faigle and Song, 2013). In sham animals, we again observed pS6positive cells mainly in the GCL (Fig. 1D). At $4 \mathrm{~h}$ after $\mathrm{CCl}$, increased pS6 signal was seen primarily in the GCL but not SGZ (Fig. 1F). At $24 \mathrm{~h}$ postinjury, a dramatic increase of pS6-positive cells showed up in the SGZ (Fig. 1H), as well as in the ML and hilus. At $48 \mathrm{~h}$ after $\mathrm{CCl}$, pS6-positive cells in the SGZ decreased compared with $24 \mathrm{~h}$, but were still more numerous than in sham surgery (Fig. 1ل). At 72 $\mathrm{h}$ and 1 week after TBI, mTORC1 activation in the SGZ was limited and comparable to that of sham animals (Fig. $1 L, N$ ). Taken together, our data enabled us to narrow down activation of $\mathrm{mTORC} 1$ in the SGZ predominantly to 24 and $48 \mathrm{~h}$ after initial insult, suggesting the potential time course of mTORC1 activation in NSCs. The duration of mTORC1 activation correlates with TBI-enhanced NSC proliferation (Gao et al., 2009), suggesting possible involvement of mTORC1 activity in TBI-enhanced NSC proliferation.

\section{TBI activates mTORC1 signaling in NSCs}

To accurately determine whether mTORC1 is activated in NSCs, we colabeled pS6 with an NSC marker. Additionally, we took advantage of a Nestin-GFP transgenic mouse, in which NSCs ectopically express green fluores- 

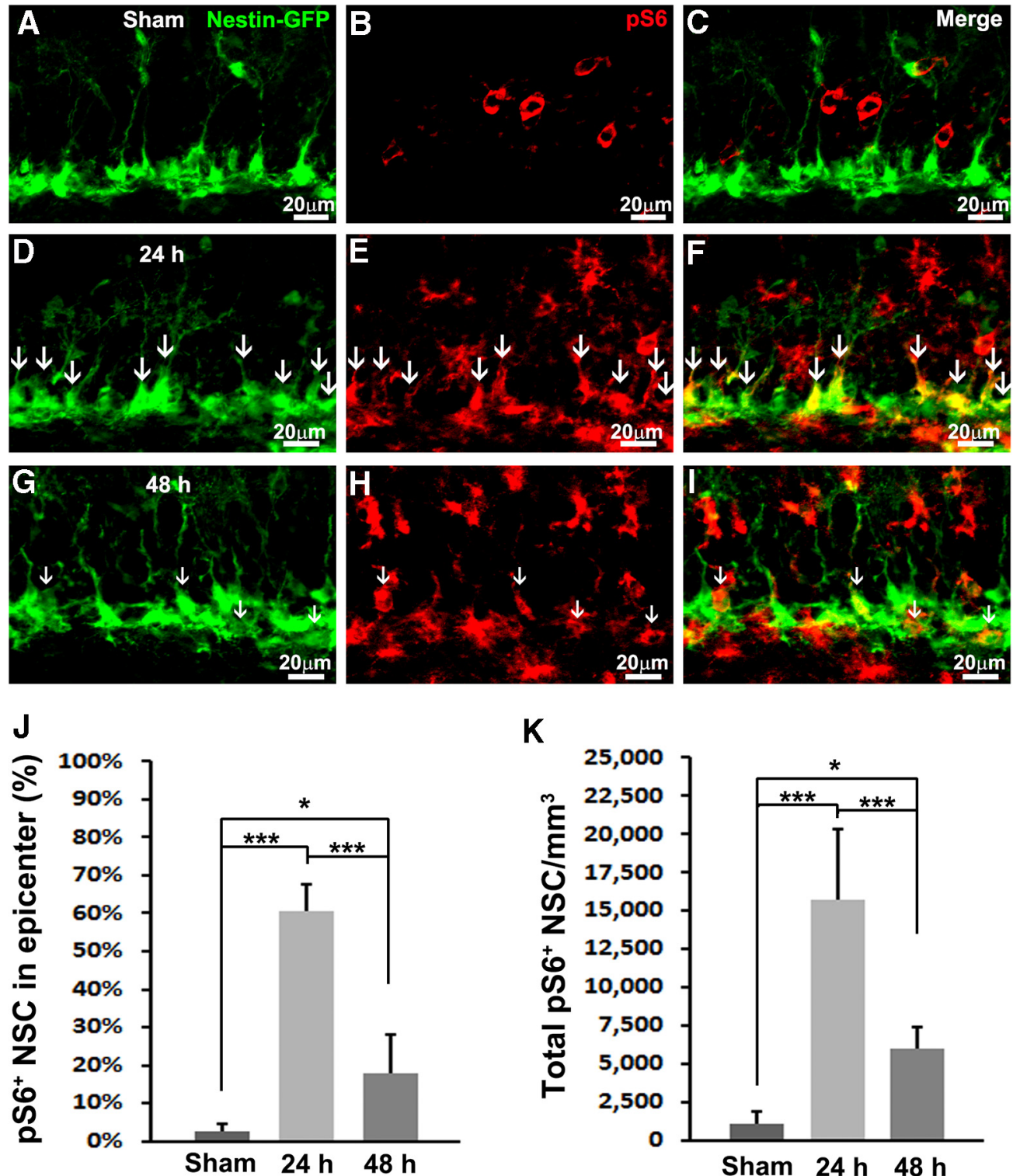

Figure 2. TBI activates mTORC1 signaling in NSCs. Mice received a moderate $\mathrm{CCl}$ at the age of 9 weeks and were sacrificed at 24 or $48 \mathrm{~h}$ after injury as well as after sham injury ( $n=5$ for each group). A-I, Immunostaining with antibodies against GFP (green) and pS6 (red) shows mTORC1 signaling activation in NSCs (white arrows) in sham animals $(\boldsymbol{A}-\boldsymbol{C}) 24 \mathrm{~h}(\boldsymbol{D}-\boldsymbol{F})$ and $48 \mathrm{~h}(\boldsymbol{G}-\boldsymbol{I})$ after $\mathrm{CCl}$ in the subgranular zone. J, Quantification of total pS6-positive NSCs after sham surgery and 24 and $48 \mathrm{~h}$ after CCI, respectively. $\boldsymbol{K}$, Quantification of percentage of pS6-positive NSCs in the epicenter after sham surgery and 24 and $48 \mathrm{~h}$ after CCl, respectively $(* p<$ $0.05, * * p<0.01, * * * p<0.001)$.

cent protein (GFP; Mignone et al., 2004; Gao et al., 2009). We hardly observed NSCs costaining with pS6 in the SGZ of sham-treated animals (Fig. 2A-C). Quantification showed that $2.6 \pm 2.1 \%$ of NSCs were pS6 positive at the epicenter (Fig. 2J). When we further examined NSCs across the whole hippocampus, only $1096 \pm 805 / \mathrm{mm}^{3}$ of total NSCs in the whole hippocampus were colabeled with pS6 (Fig. 2K). These results confirmed our prior notion that mTORC1 activity in the NSCs is very low in the sham-treated animals.

At $24 \mathrm{~h}$ after TBI, the number of pS6-positive cells in the SGZ was dramatically increased (Fig. 2E) and largely labeled NSCs (Fig. 2D-F, white arrows). Quantification showed that mTORC1 is active in $60.7 \pm 6.8 \%$ of total
NSCs in the epicenter $\left(F_{(2,12)}=35.077, p<0.001^{\mathrm{c}}\right.$; Fig. 2J). In all, mTORC1 signaling is active in $15750 \pm 4620 /$ $\mathrm{mm}^{3}$ NSCs across the whole hippocampus $\left(F_{(2,12)}=\right.$ 85.257, $p<0.001^{\text {d }}$; Fig. $\left.2 K\right)$, indicating a dramatic 15-fold increase compared with sham control.

At $48 \mathrm{~h}$ after $\mathrm{CCl}$, the number of pS6-positive cells was still very high (Fig. $2 H$ ), whereas labeling in NSCs decreased (Fig. 2G-l, white arrows). At the epicenter, the percentage of mTORC1-positive NSCs also dropped to $17.7 \pm 10.4 \%\left(F_{(2,12)}=35.077, p<0.001^{\circ}\right.$ vs. $24 \mathrm{~h}, p=$ $0.017^{c}$ vs. sham; Fig. $2 J$ ). The number of NSCs with active mTORC1 across the whole hippocampus rapidly decreased to $5987 \pm 1348 / \mathrm{mm}^{3}\left(F_{(2,12)}=85.257, p<0.001^{\mathrm{d}}\right.$ vs. $24 \mathrm{~h})$ but was still much higher than basal level $\left(F_{(2,12)}\right.$ 
$=85.257, p=0.044^{\mathrm{d}}$ vs. sham; Fig. $2 K$ ). In all, we observed a rapid and robust activation of $\mathrm{mTORC} 1$ in NSCs $24 \mathrm{~h}$ after TBI that lasted at least to $48 \mathrm{~h}$ after trauma.

\section{TBI activates mTORC1 signaling in proliferating NSCs}

Previously, it was proven that TBI transiently promoted NSC proliferation around 24-48 h postinjury (Gao and Chen, 2013). The molecular mechanisms that mediate TBI-enhanced NSC proliferation are completely unknown. The timing of $\mathrm{mTORC} 1$ signaling activation correlates well with NSC proliferation after TBI, strongly suggesting that mTORC1 signaling activation is involved in regulating TBIinduced NSC proliferation. Thus we further assessed whether mTORC1 signaling is activated in proliferating NSCs. BrdU injection (i.p., $100 \mathrm{mg} / \mathrm{kg}$ ) was given $4 \mathrm{~h}$ before sacrifice (Fig. $3 A$ ), and the proliferating cells during this $4 \mathrm{~h}$ period were pulse-labeled. Series of every sixth section were processed for triple immunostaining to assess mTORC1 activity in proliferating NSCs.

In sham-treated animals, only $2320 \pm 513 / \mathrm{mm}^{3} \mathrm{NSCs}$ were proliferating, as pulse-labeled by BrdU (Fig. 3B, C, E, white arrowheads, and Fig. $3 N$ ). Among these proliferating NSCs, only $49 \pm 40 / \mathrm{mm}^{3}$ of them were pS6 positive (Fig. 30 ), representing only $1.9 \pm 1.2 \%$ of total proliferating NSCs that were pS6 positive (Fig. 3Q). These data indicate that only a small population of NSCs are proliferating in the hippocampus of mice receiving sham surgery, and the activity of mTORC1 signaling at these proliferating NSCs is extremely low.

Twenty-four hours after receiving moderate $\mathrm{CCl}$ injury, $3070 \pm 658 / \mathrm{mm}^{3}$ NSCs were proliferating in the hippocampus of the mice (Fig. 3F, G, I, white arrowhead and arrow, and Fig. $3 N$ ). However, TBI significantly activated mTORC1 signaling in the hippocampus (Fig. $3 H$ ). Of the proliferating NSCs, $649 \pm 229 / \mathrm{mm}^{3}$ or $24.7 \pm 6.2 \%$ were pS6 positive (Fig. 3F-I, white arrow, and Fig. 3O, Q), whereas the rest of the proliferating NSCs were pS6 negative (Fig. $3 F-I$, white arrowhead). These results indicate TBI did not dramatically alter NSC proliferation at 24 h compared with sham animals $\left(F_{(2,12)}=20.432, p=\right.$ $0.328^{\mathrm{e}}$; Fig. $3 N$ ), which has been demonstrated before (Gao and Chen, 2013); however, TBI promoted a 13-fold increase of mTORC1 activation in the proliferating NSCs $24 \mathrm{~h}$ after TBI $\left(F_{(2,12)}=17.037, p=0.001^{\mathrm{h}}\right.$; Fig. 3Q).

Forty-eight hours after receiving moderate $\mathrm{CCl}$ injury, $5396 \pm 1092 / \mathrm{mm}^{3}$ NSCs were proliferating in the hippocampus of the mice (Fig. $3 J, K, M$, arrowheads and arrows, and Fig. $3 \mathrm{~N}$ ). TBI dramatically increased the proliferation of NSCs in the hippocampus at this time point $\left(F_{(2,12)}=20.432, p<0.001^{\mathrm{e}}\right)$, agreeing with a previous report that TBI transiently promoted NSC proliferation 48 h after TBI (Gao and Chen, 2013). TBI also significantly promoted mTORC1 signaling in the proliferating NSCs $\left(1260 \pm 798 / \mathrm{mm}^{3}, F_{(2,12)}=7.954, p=0.005^{\dagger}\right.$ vs. sham; Fig. 3J-M, white arrows, and Fig. 3O). These data indicate that TBI significantly promotes NSC proliferation (Fig. $3 N$ ) and enhanced mTORC1 activity in the proliferating NSCs $48 \mathrm{~h}$ after injury (Fig. 30, Q). In all, we observed a dra- matically increased level of mTORC1 activation in proliferating NSCs 24 and $48 \mathrm{~h}$ after TBI, and TBI transiently promoted NSC proliferation beginning $48 \mathrm{~h}$ after TBI. The sequence of mTORC1 activation and NSC proliferation strongly suggest the possible involvement of mTORC1 signaling pathway activation in TBI-enhanced NSC proliferation.

\section{Inhibition of mTORC1 signaling eliminates TBI- enhanced NSC proliferation}

To further confirm that mTORC1 activation is required for TBI-enhanced NSC proliferation, we treated TBI animals with rapamycin, a well-established mTORC1 inhibitor, and evaluated NSC proliferation $48 \mathrm{~h}$ after TBI. To fully block mTORC1 activity, four injections of rapamycin (i.p., $10 \mathrm{mg} / \mathrm{kg}$ ) or vehicle were given at $12,24,36$, and $44 \mathrm{~h}$ after TBI or sham surgery. Immediately after the last rapamycin injection, a dose of BrdU (i.p., $100 \mathrm{mg} / \mathrm{kg}$ ) was given to label cell proliferation, and then animals were perfused at $48 \mathrm{~h}$ after injury (Fig. $4 A$ ).

To evaluate mTORC1 inhibition, the epicenter section from each animal was processed for pS6 staining. The low-level mTORC1 activation in sham animals was not apparently affected by rapamycin (Fig. $4 B, D$ ), whereas the originally strong mTORC1 activation in the HDG was dramatically abolished in TBI animals $48 \mathrm{~h}$ after surgery (Fig. 4C, E). pS6 staining demonstrated successful mTORC1 inhibition in the HDG after trauma. To assess overall cell proliferation, the epicenter section from each animal was processed for BrdU staining. An obvious decrease of BrdU-positive cells in the HDG was observed in both rapamycin-treated sham and TBI animals compared with vehicle groups (Fig. 4F-l). These data indicate that inhibition of mTORC1 dramatically reduces cell proliferation in the hippocampus.

Different types of cells, including glia and NSCs, proliferate after TBI. To further determine whether inhibition of mTORC1 affects NSC proliferation, double immunostaining with an NSC marker was performed (Fig. 5). In sham control animals treated with vehicle, there were $1925 \pm$ $313 / \mathrm{mm}^{3}$ NSCs proliferating (Fig. $5 A-C$, arrows, and Fig. $5 M)$, which was slightly decreased by rapamycin treatment to $1436 \pm 519 / \mathrm{mm}^{3}$, without significant difference $\left(F_{(1,19)}=7.543, p=0.956^{9}\right.$; Fig. 5D-F, M). After TBI, NSC proliferation was dramatically increased to $4260 \pm 1251$ / $\mathrm{mm}^{3}\left(F_{(1,19)}=20.233, p=0.001^{i}\right.$ vs. sham + vehicle; Fig. $5 G-I, M)$, whereas rapamycin treatment abolished the enhanced effect on NSC proliferation $\left(2375 \pm 920 / \mathrm{mm}^{3}\right.$, $F_{(1,19)}=7.543, p=0.018^{i}$ vs. TBI + vehicle; Fig. $\left.5 J-L, M\right)$. Altogether, our data suggest that inhibition of mTORC1 signaling eliminates TBI-enhanced NSC proliferation, indicating that mTORC1 signaling pathway activation is required for TBI-enhanced NSC proliferation.

\section{Discussion}

TBI induces dramatic cell death in the hippocampus, which contributes to vast disconnections of local neurocircuitries and subsequent neurobehavioral dysfunctions. So far, no Food and Drug Administration-approved drug against neuronal loss caused by TBI is available, and effective neuroprotective or alternative neural repair ap- 

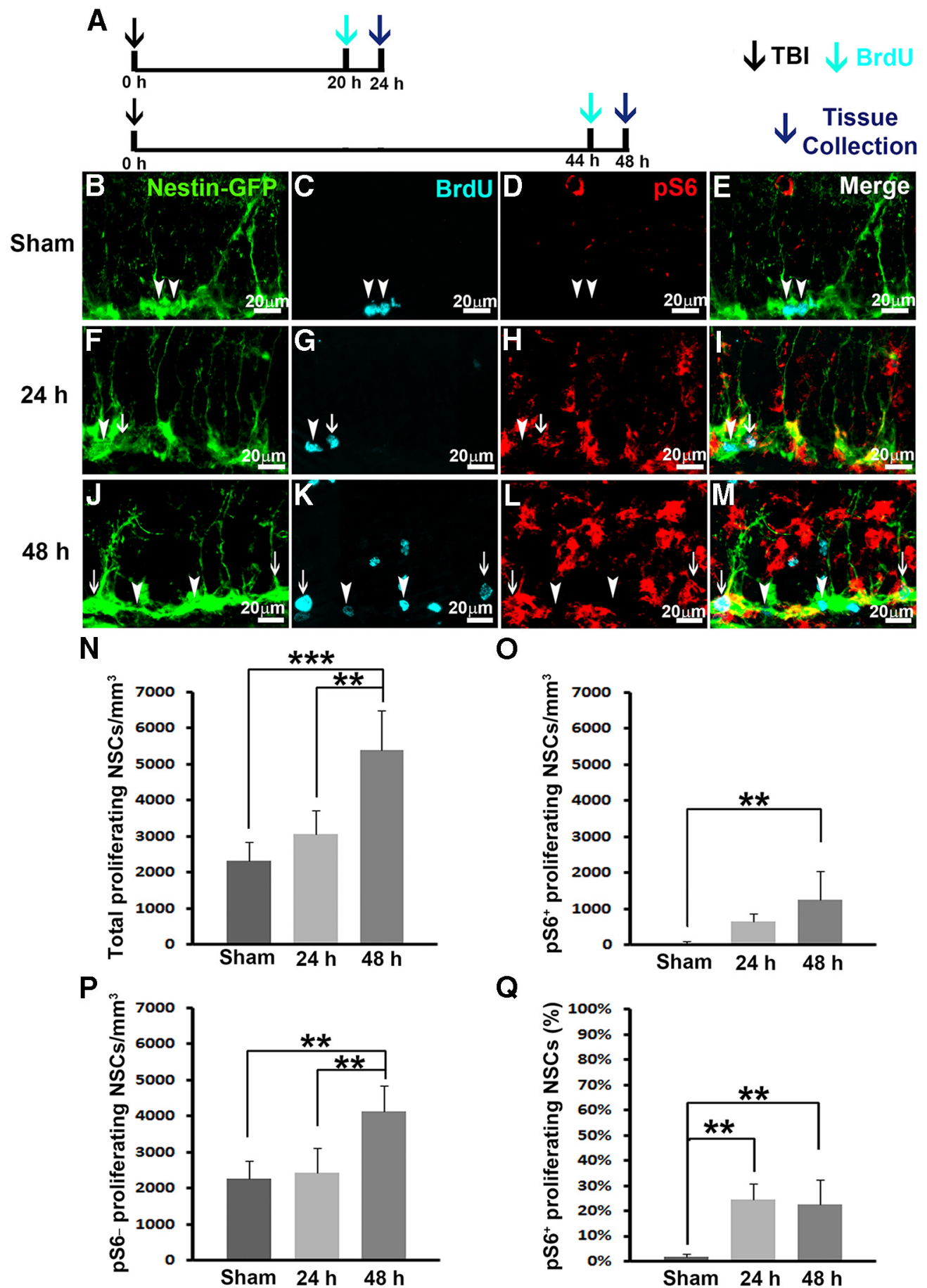

Q

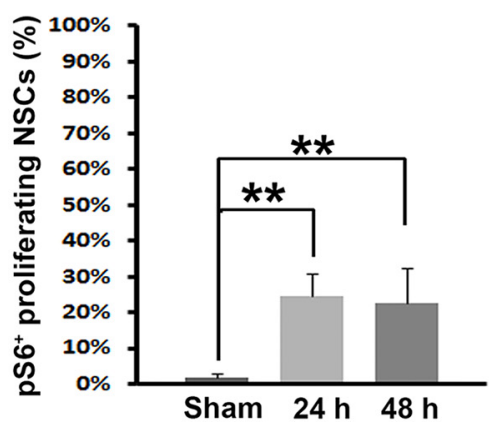

Figure 3. TBI activates mTORC1 signaling in proliferating NSCs. Mice received a moderate $\mathrm{CCl}$ at the age of 9 weeks and were sacrificed at 24 or $48 \mathrm{~h}$ after injury as well as after sham injury ( $n=5$ for each group). A dose of BrdU was administered $4 \mathrm{~h}$ before perfusion. A, Experimental strategy. $\boldsymbol{B}-\boldsymbol{M}$, Immunostaining with antibodies against GFP (green), BrdU (cyan), and pS6 (red) shows proliferating NSCs with (white arrows) or without (arrowheads) mTORC1 signaling activation in sham animals $(\boldsymbol{B}-\boldsymbol{E}), 24 \mathrm{~h}(\boldsymbol{F}-\boldsymbol{I})$ and 48 h $(\boldsymbol{J}-\boldsymbol{M})$ after $\mathrm{CCl}$ in the subgranular zone. $\mathbf{N}-\boldsymbol{P}$, Quantification of total proliferating NSCs $(\boldsymbol{N})$, total pS6-positive proliferating NSCs $(\mathbf{O})$, and total pS6-negative proliferating NSCs $(\boldsymbol{P})$ after sham surgery and 24 and $48 \mathrm{~h}$ after $\mathrm{CCl}$, respectively. $\boldsymbol{Q}$, Quantification of percentage of pS6-positive proliferating NSCs after sham surgery and 24 and $48 \mathrm{~h}$ after CCl, respectively $(* p<0.05, * * p<0.01, * * * p$ $<0.001)$.

proaches are urgently needed. NSCs in the hippocampus represent the potential of neuroregeneration in the adult brain and hold great promise for neuronal replacement after trauma (Kuhn et al., 1996; Shapiro and Ribak, 2005;
Ming and Song, 2005; Zhao et al., 2006). It has been widely reported that NSC proliferation increases after TBI (Dash et al., 2001; Kernie et al., 2001; Braun et al., 2002; Chirumamilla et al., 2002; Rice et al., 2003; Ramaswamy 

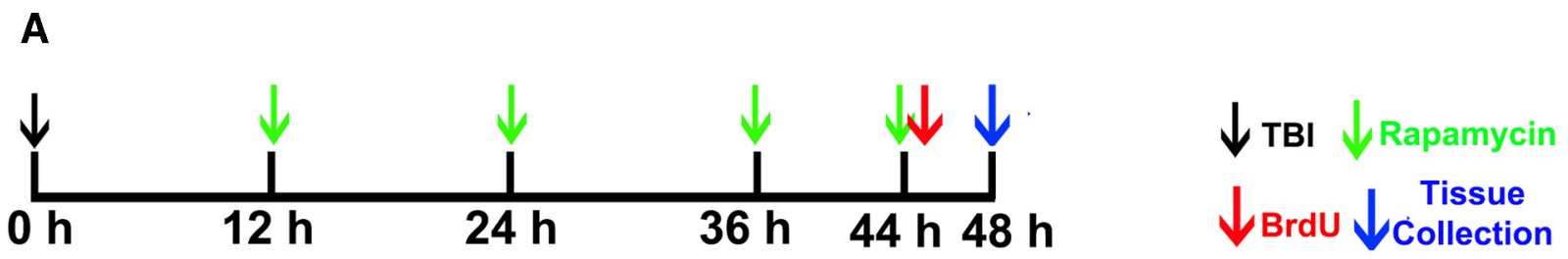

Vehicle
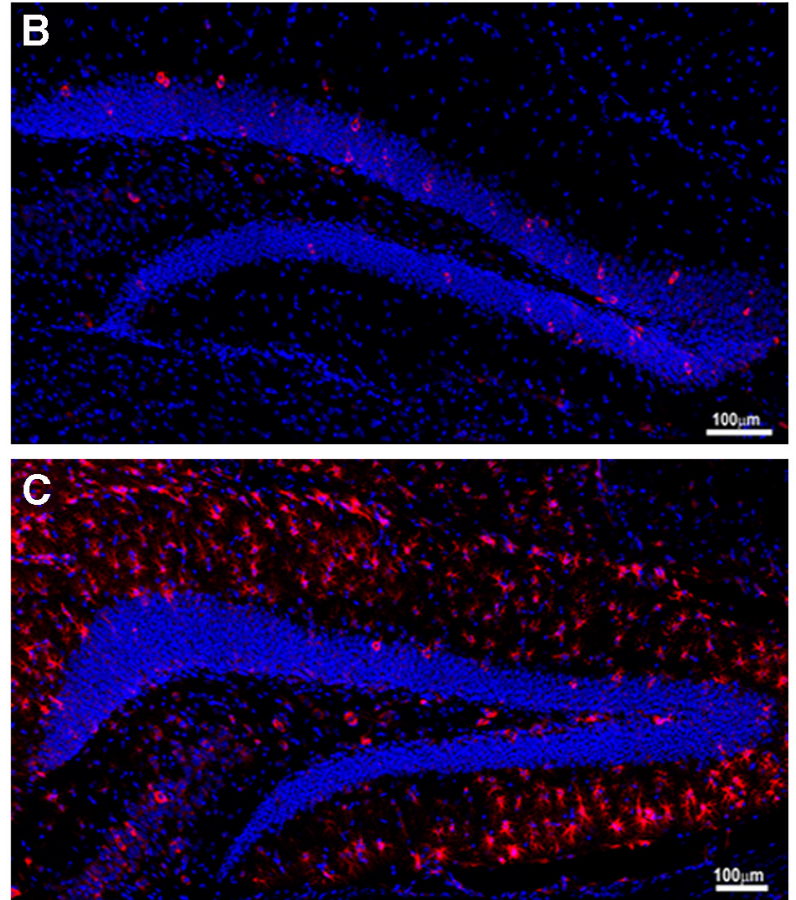

Vehicle

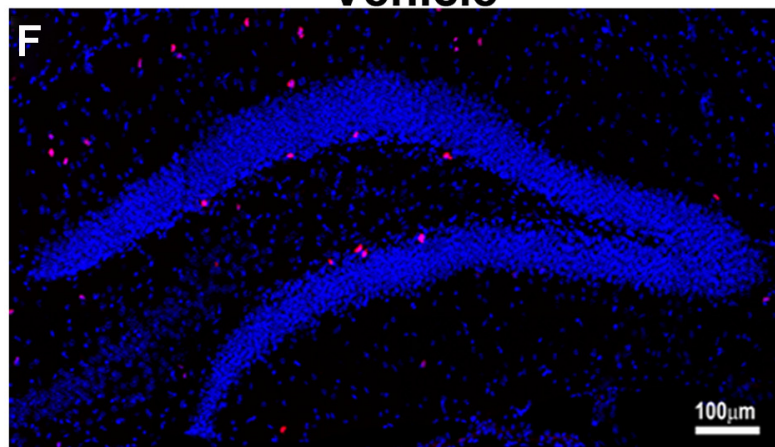

G

TBI
Rapamycin

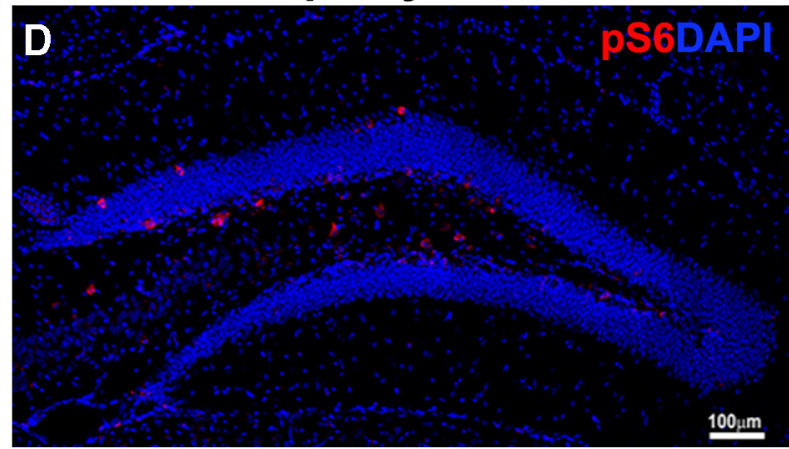

E

$100 \mu \mathrm{m}$

Rapamycin

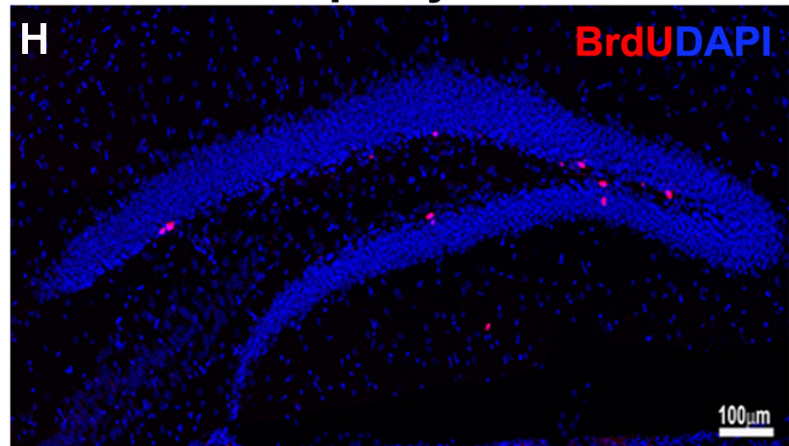

I

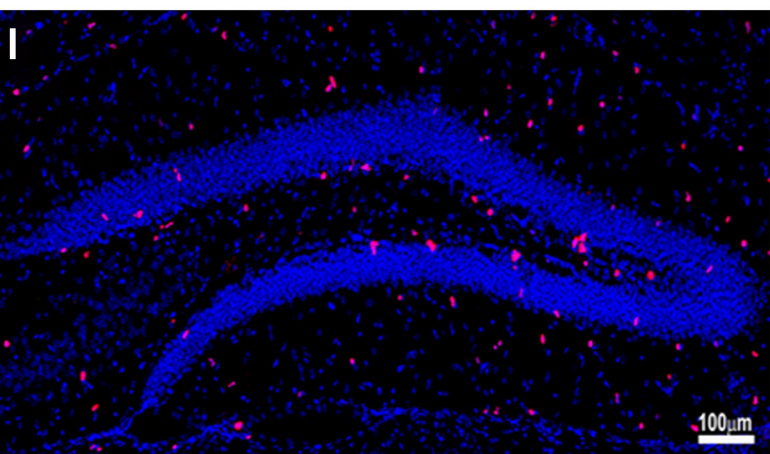

Figure 4. Rapamycin treatment inhibits mTORC1 signaling and cell proliferation in the hippocampus after TBI. $\boldsymbol{A}$, Experimental strategy. $\boldsymbol{B}-\boldsymbol{E}$, Immunostaining with antibody against pS6 (red) shows mTORC1 signaling activity after rapamycin or vehicle treatment 
continued

in sham animals or $48 \mathrm{~h}$ after CCl. $\boldsymbol{F}-\mathbf{I}$, Immunostaining with antibodies against BrdU (red) shows cell proliferation in the HDG after rapamycin or vehicle treatment in sham animals or $48 \mathrm{~h}$ after $\mathrm{CCI}$. DAPI staining shows structure of HDG.

et al., 2005; Sun et al., 2005; Gao et al., 2009; Zheng et al., 2013), as well as production of mature neurons in some circumstances (Sun et al., 2005, 2007; Wang et al., 2016). This phenomenon shows the regenerative potential of adult brain by neurogenic response of NSCs after TBI. However, the increased NSC proliferation does not always result in enhanced neurogenesis (Gao and Chen, 2013; Wang et al., 2016). Therefore, the innate response is not always strong enough to fully compensate for neuronal loss, and thus approaches are needed to further promote NSC proliferation after trauma. Unfortunately the molecular mechanisms underlying TBI-enhanced NSC proliferation are currently unknown, largely impeding its application.

Neural stem/progenitor cells in the hippocampus can be categorized into at least two subtypes based on morphology, protein marker expression, and pattern of division (Seri and García-Verdugo, 2001; Seaberg and van der Kooy, 2002; Filippov et al., 2003; Mignone et al., 2004; Bull and Bartlett, 2005; Encinas et al., 2006, 2008; Encinas and Enikolopov, 2008). Only a small fraction (1.73\%) of radial glia-like type I NSCs can be labeled with BrdU after a short (4-h) pulse (Gao et al., 2009), indicating that they are normally quiescent (Mignone et al., 2004; Encinas et al., 2006); hence they are designated as quiescent neural stem cells (qNSCs) or active neural stem cells (aNSCs) depending on whether they are active in proliferation. Under basal conditions, qNSCs play the role of stem cells, whereas aNSCs undergo asymmetric divisions to generate small round or oval-shaped type II neural progenitor cells (NPCs). These progeny cells undergo a series of symmetric divisions and can be labeled with BrdU with high frequency. After a short (4-h) pulse, $14.99 \%$ of NPCs can be labeled with BrdU (Gao et al., 2009); they are described as amplifying neural progenitor cells (aNPCs; Mignone et al., 2004; Encinas et al., 2006). It has been recently found that TBI activates quiescent qNSCs. The percentage of proliferating qNSCs was significantly increased from $1.73 \pm 0.16 \%$ to $3.76 \pm 0.48 \%$, a 2.17-fold difference (Gao et al., 2009), indicating that TBI may release a subpopulation of qNSCs from quiescent status and promote them to reenter the cell cycle, thus becoming active NSCs (aNSCs). The activation of qNSCs by TBI is transient. The NSCs reverted back to quiescence in a few days after TBI, indicating that quiescence and proliferation are reversible (Fig. 6). The molecular mechanisms that activate qNSCs after TBI are completely unknown.

Cellular quiescence is a reversible nonproliferating state and outside of an active cell cycle (also called G0; Infante et al., 2008; Coller, 2011). Quiescence serves an essential role in preserving stem cell function until the stem cell is needed in tissue homeostasis or repair. Cell quiescence and proliferation are tightly regulated to maintain tissue homeostasis (Coller, 2011; Hilpert et al., 2014; Lin et al., 2014; Rodgers et al., 2014). The reactivation of qNSCs into proliferation is crucial for tissue repair and regeneration. This reactivation not only exists in neural stem cells, but it also occurs in other tissue stem cells such as fibroblasts and hematopoietic stem cells (Rumman et al., 2015). Studies in the past few years have revealed that, instead of being a passive state, quiescence is actively maintained in the cell (Spencer et al., 2013; Hilpert et al., 2014). Quiescent cells are transcriptionally active. The extent to which stem cells can regulate quiescence and reactivation is very poorly understood. Our present study, in a rodent $\mathrm{CCl}$ model, demonstrates that $\mathrm{MTORC} 1$ activation is required for activating quiescent NSCs by TBI. Our result demonstrates that mTOR signaling is a key regulator of the stem cell fate choice. We provide a model of reactivation of quiescent neural stem cells for brain repair after injury (Fig. 6). This reactivation can potentially be targeted for interventions on NSC activity and concomitant neuronal replacement for functional recovery after trauma.

As a fundamental pathway in all types of cells, mTOR signaling is involved in many important cellular events, including metabolism, cell growth, cell cycle progression, and cell survival (Laplante and Sabatini, 2012). Specifically in the nervous system, particularly in NSCs, mTOR signaling, especially mTORC1, is also significant for balancing self-renewal and differentiation. It has been reported that constitutive hyperactivity of mTORC1 signaling is responsible for deregulated NSCs activity in the embryonic stage and leads to tuberous sclerosis development (Magri et al., 2011). In postnatal development, mTORC1 activity is also required for NSCs, especially in maintenance of the transit amplifying neural progenitor pool (Paliouras et al., 2012). Decline of NSC proliferation in aging rodents can also be restored by activating mTORC1 activity (Romine et al., 2015). Collectively, mTORC1 plays significant roles in regulating NSC activity, particularly in regulating NSC proliferation. After TBI, activation of mTORC1 signaling in the injured cortex and hippocampus has been noticed for a while (Chen et al., 2007; Park et al., 2012); however, the role of mTORC1 activation remains elusive. Initially, mTORC1 was proven to mediate apoptotic neuronal death within hours after $\mathrm{TBI}$, and early inhibition of mTORC1 signaling by rapamycin pretreatment has been shown to alleviate motor deficits and cognitive impairments 3 days after trauma (Park et al., 2012; Ding et al., 2015). Later on, mTORC1 activation in microglia and astrocytes postinjury has further been noticed, thus bringing about the idea that roles of mTORC1 in TBI pathogenesis include inducing neuroinflammation and promoting astrogliosis, which was also reversed by rapamycin administration (Ding et al., 2014; Nikolaeva et al., 2015). Besides, genetic activation of mTORC1 by upstream negative regulator inactivation worsens cognitive performances after TBI in rodents (Rozas et al., 2015). Recently, Butler et al. (2015) pointed out a regulatory role of $\mathrm{mTORC} 1$ in neurogenesis and synap- 

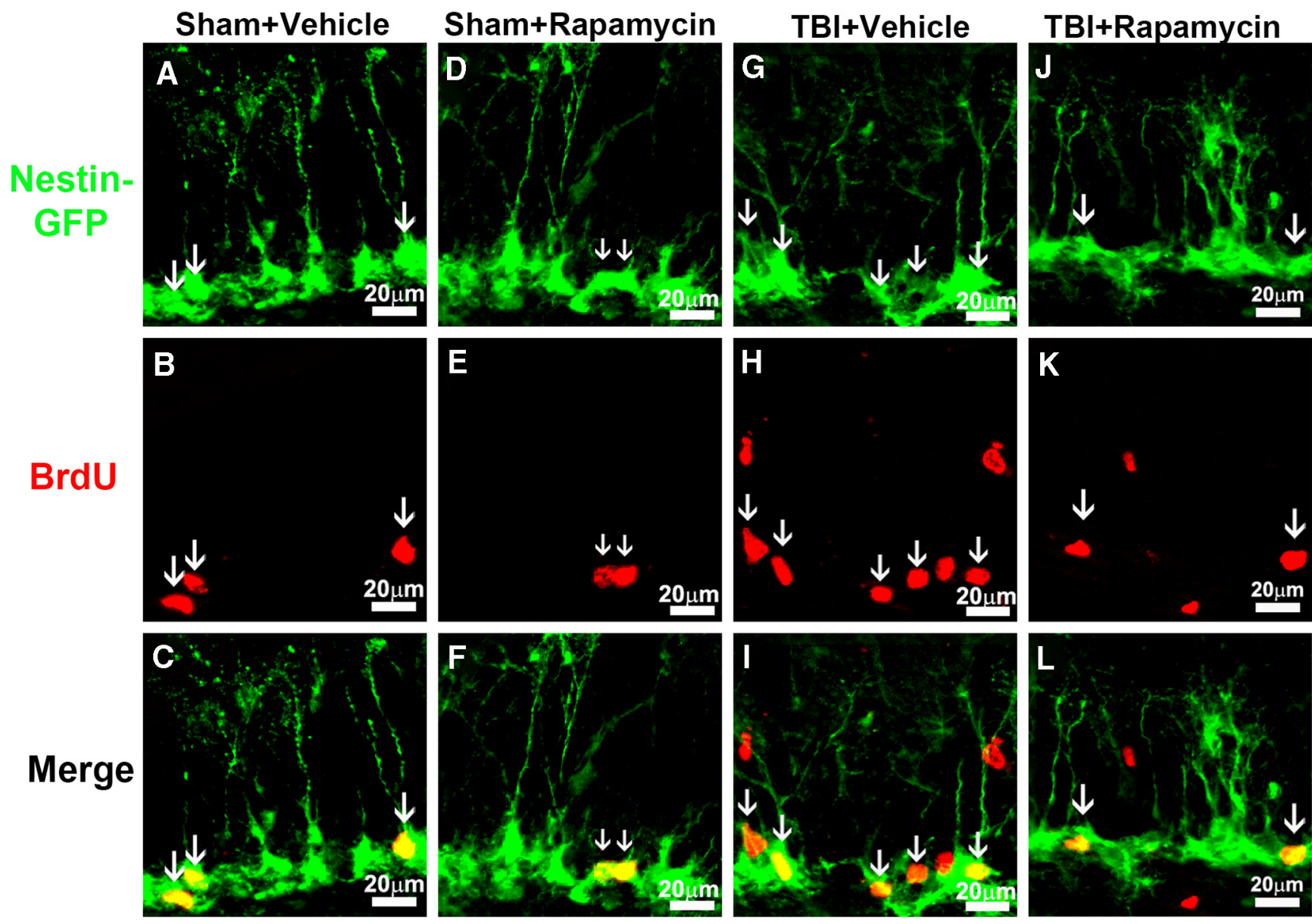

M

NSC proliferation

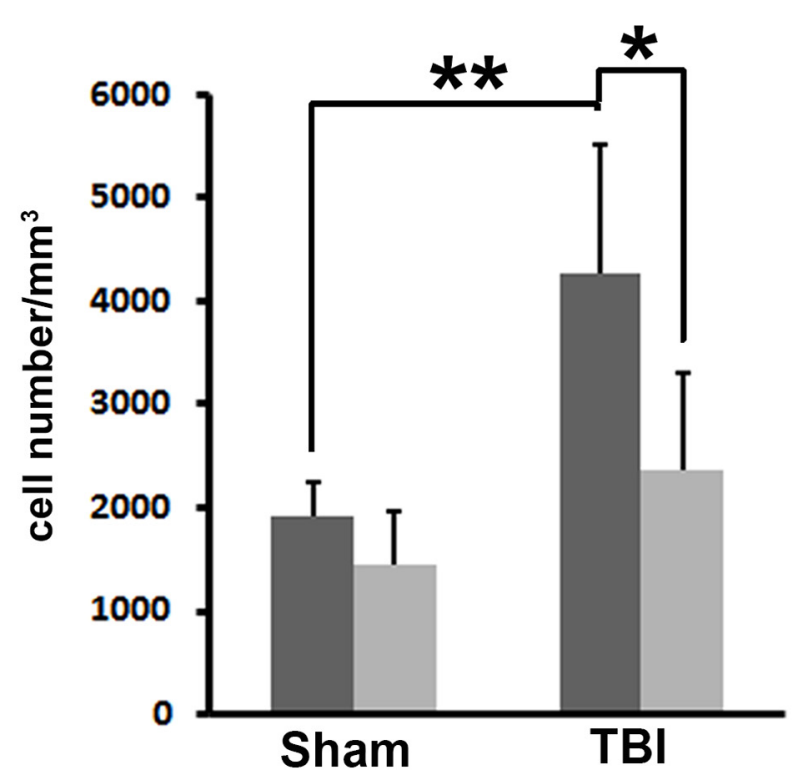

Vehicle

Rapamycin

Figure 5. Inhibition of mTORC1 signaling ablates TBI-enhanced NSC proliferation. Mice were treated with the same procedure as in Figure $4 A$ ( $n=5$ for each group). A-L, Immunostaining with antibodies against GFP (green) and BrdU (red) shows NSC proliferation (white arrows) in the SGZ after rapamycin or vehicle treatment in sham animals and $48 \mathrm{~h}$ after CCl. $\mathbf{M}$, Quantification of NSC proliferation in the SGZ after rapamycin or vehicle treatment in sham animals and $48 \mathrm{~h}$ after $\mathrm{CCl}(* p<0.05, * * p<0.01, * * * p<0.001)$. 


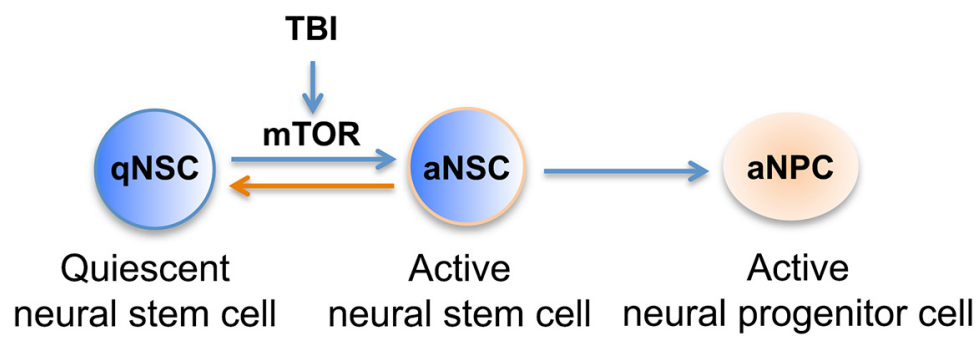

Figure 6. Reactivation of quiescent neural stem cells after TBI. Quiescence differs from other nondividing states in that it can be reverted into proliferation. TBI activates mTOR in NSCs, which is essential for NSCs to exit quiescence and enter proliferation.

tic reorganization after TBI, which was potentially involved in post-traumatic epileptogenesis. Altogether, mTORC1 activation was considered a deleterious event after TBI; thus it was targeted in most studies. However, another study demonstrated that rapamycin treatment worsened cognitive deficits instead (Zhu et al., 2014). Our unpublished data also indicate that mTOR activation is required for survival of spared neurons in the injured cortex. The exact role of mTOR in TBI pathophysiology has yet to be determined. In our present study, we focused on the regulatory role of $\mathrm{mTORC} 1$ especially in NSC proliferation after moderate $\mathrm{TBI}$ using a $\mathrm{CCl}$ model in rodents. We illustrated that mTORC1 activation in NSCs in the hippocampus was delayed to 24-48 $\mathrm{h}$ after initial injury compared with $4 \mathrm{~h}$ after trauma in mature neurons reported by other studies (Chen et al., 2007; Ding et al., 2015). In addition, inhibition by rapamycin abolished TBIenhanced NSC proliferation in the hippocampus $48 \mathrm{~h}$ after moderate $\mathrm{CCl}$. This study demonstrates a beneficial role of mTORC1 in neuroplasticity by mediating NSC proliferation after TBI. Although some studies proved that inhibition of mTORC1 activity after TBI by pre- or posttreatment with rapamycin improved motor functions and cognitive outcomes at the acute phase after TBI, the present results suggest that these regimens may come at the expense of compromising long-term neuroregeneration. In contrast, short-term enhancing mTOR activation may increase neurogenesis and have a long-term effort in improving learning and memory functions after TBI. In all, the role of mTOR activation is specific to cell type and time course in TBI pathophysiology. Thus a detailed spatial-temporal profile of mTOR activation is required, before clearly determining the therapeutic potential of inhibition or activation of its activity, as well as when and where mTOR activity should be modulated in terms of beneficial neurobehavioral outcomes in TBI patients. Meanwhile, as a multifunctional signaling pathway, mTOR may not be a good target for therapeutic applications. Further investigations are needed to determine specific downstream targets of mTOR in different scenarios of individual cell types, namely mature neuron apoptosis, NSC proliferation, microglia activation-mediated neuroinflammation, and astrogliosis.

\section{References}

Akers KG, Martinez-Canabal A, Restivo L, Yiu AP, De Cristofaro A, Hsiang HL, Wheeler AL, Guskjolen A, Niibori Y, Shoji H, Ohira K, Richards BA, Miyakawa T, Josselyn SA, Frankland PW (2014)
Hippocampal neurogenesis regulates forgetting during adulthood and infancy. Science 344:598-602. CrossRef

Blaiss CA, Yu TS, Zhang G, Chen J, Dimchev G, Parada LF, Powell CM, Kernie SG (2011) Temporally specified genetic ablation of neurogenesis impairs cognitive recovery after traumatic brain injury. J Neurosci 31:4906-4916. CrossRef

Braun H, Schäfer K, Höllt V (2002) Betalll tubulin-expressing neurons reveal enhanced neurogenesis in hippocampal and cortical structures after a contusion trauma in rats. J Neurotrauma 19:975-983. CrossRef

Bull ND, Bartlett PF (2005) The adult mouse hippocampal progenitor is neurogenic but not a stem cell. $\mathrm{J}$ Neurosci $25: 10815-10821$. CrossRef Medline

Butler CR, Boychuk JA, Smith BN (2015) Effects of rapamycin treatment on neurogenesis and synaptic reorganization in the dentate gyrus after controlled cortical impact injury in mice. Front Syst Neurosci 9:163. CrossRef

Cameron HA, McKay RD (2001) Adult neurogenesis produces a large pool of new granule cells in the dentate gyrus. J Comp Neur 435:406-417. Medline

Chen S, Atkins CM, Liu CL, Alonso OF, Dietrich WD, Hu BR (2007) Alterations in mammalian target of rapamycin signaling pathways after traumatic brain injury. J Cereb Blood Flow Metab 27:939949.

Chirumamilla S, Sun D, Bullock MR, Colello RJ (2002) Traumatic brain injury induced cell proliferation in the adult mammalian central nervous system. J Neurotrauma 19:693-703. CrossRef Medline

Christian KM, Song H, Ming GL (2014) Functions and dysfunctions of adult hippocampal neurogenesis. Annu Rev Neurosci 37:243-262. CrossRef Medline

Cicerone KD, Dahlberg C, Malec JF, Langenbahn DM, Felicetti T, Kneipp S, Ellmo W, Kalmar K, Giacino JT, Harley JP, Laatsch L, Morse PA, Catanese J (2005) Evidence-based cognitive rehabilitation: updated review of the literature from 1998 through 2002. Arch Phys Med Rehabil 86:1681-1692. CrossRef

Colicos MA, Dixon CE, Dash PK (1996) Delayed, selective neuronal death following experimental cortical impact injury in rats: possible role in memory deficits. Brain Res 739:111-119. CrossRef

Coller HA (2011) Cell biology. The essence of quiescence. Science 334:1074-1075. CrossRef Medline

Dash PK, Mach SA, Moore AN (2001) Enhanced neurogenesis in the rodent hippocampus following traumatic brain injury. J Neurosci Res 63:313-319. CrossRef Medline

Ding K, Wang H, Wu Y, Zhang L, Xu J, Li T, Ding Y, Zhu L, He J (2015) Rapamycin protects against apoptotic neuronal death and improves neurologic function after traumatic brain injury in mice via modulation of the mTOR-p53-Bax axis. J Surg Res 194:239-247. CrossRef

Ding K, Wang H, Xu J, Lu X, Zhang L, Zhu L (2014) Melatonin reduced microglial activation and alleviated neuroinflammation induced neuron degeneration in experimental traumatic brain injury: possible involvement of mTOR pathway. Neurochem Int 76: 23-31. CrossRef 
Emery DL, Fulp CT, Saatman KE, Schütz C, Neugebauer E, McIntosh TK (2005) Newly born granule cells in the dentate gyrus rapidly extend axons into the hippocampal CA3 region following experimental brain injury. J Neurotrauma 22:978-988. CrossRef

Encinas JM, Enikolopov G (2008) Identifying and quantitating neural stem and progenitor cells in the adult brain. Methods Cell Biol 85:243-272

Encinas JM, Vaahtokari A, Enikolopov G (2006) Fluoxetine targets early progenitor cells in the adult brain. Proc Natl Acad Sci U S A 103:8233-8238. CrossRef Medline

Encinas JM, Vazquez ME, Switzer RC, Chamberland DW, Nick H, Levine HG, Scarpa PJ, Enikolopov G, Steindler DA (2008) Quiescent adult neural stem cells are exceptionally sensitive to cosmic radiation. Exp Neurol 210:274-279. CrossRef Medline

Eriksson PS, Perfilieva E, Björk-Eriksson T, Alborn AM, Nordborg C, Peterson DA, Gage FH (1998) Neurogenesis in the adult human hippocampus. Nat Med 4:1313-1317. CrossRef Medline

Faigle R, Song H (2013) Signaling mechanisms regulating adult neural stem cells and neurogenesis. Biochim Biophys Acta 1830: 2435-2448. CrossRef Medline

Faul M. X. L., Wald MM, Coronado VG 2010. Traumatic brain injury in the United States: emergency department visits, hospitalizations, and deaths. Centers for Disease Control and Prevention, National Center for Injury Prevention and Control: Atlanta.

Filippov V, Kronenberg G, Pivneva T, Reuter K, Steiner B, Wang LP, Yamaguchi M, Kettenmann H, Kempermann G (2003) Subpopulation of nestin-expressing progenitor cells in the adult murine hippocampus shows electrophysiological and morphological characteristics of astrocytes. Mol Cell Neurosci 23:373-382. CrossRef

Gao X, Chen J (2013) Moderate traumatic brain injury promotes neural precursor proliferation without increasing neurogenesis in the adult hippocampus. Exp Neurol 239:38-48. CrossRef

Gao X, Deng-Bryant Y, Cho W, Carrico KM, Hall ED, Chen J (2008) Selective death of newborn neurons in hippocampal dentate gyrus following moderate experimental traumatic brain injury. J Neurosci Res 86:2258-2270. CrossRef

Gao X, Enikolopov G, Chen J (2009) Moderate traumatic brain injury promotes proliferation of quiescent neural progenitors in the adult hippocampus. Exp Neurol 219:516-523. CrossRef Medline

Hall ED, Sullivan PG, Gibson TR, Pavel KM, Thompson BM, Scheff SW (2005) Spatial and temporal characteristics of neurodegeneration after controlled cortical impact in mice: more than a focal brain injury. J Neurotrauma 22:252-265. CrossRef

Hartman NW, Lin TV, Zhang L, Paquelet GE, Feliciano DM, Bordey A (2013) mTORC1 targets the translational repressor 4E-BP2, but not S6 kinase 1/2, to regulate neural stem cell self-renewal in vivo. Cell Rep 5:433-444. CrossRef Medline

Hicks R, Soares H, Smith D, Mclntosh T (1996) Temporal and spatial characterization of neuronal injury following lateral fluidpercussion brain injury in the rat. Acta Neuropathol 91:236-246. CrossRef

Hilpert M, Legrand C, Bluteau D, Balayn N, Betems A, Bluteau O, Villeval JL, Louache F, Gonin P, Debili N, Plo I, Vainchenker W, Gilles L, Raslova H (2014) p19 INK4d controls hematopoietic stem cells in a cell-autonomous manner during genotoxic stress and through the microenvironment during aging. Stem Cell Rep 3:1085-1102. CrossRef

Infante A, Laresgoiti U, Fernández-Rueda J, Fullaondo A, Galán J, Diaz-Uriarte R, Malumbres M, Field SJ, Zubiaga AM (2008) E2F2 represses cell cycle regulators to maintain quiescence. Cell Cycle 7:3915-3927. CrossRef Medline

Kernie SG, Erwin TM, Parada LF (2001) Brain remodeling due to neuronal and astrocytic proliferation after controlled cortical injury in mice. J Neurosci Res 66:317-326. CrossRef

Kitamura T, Saitoh Y, Takashima N, Murayama A, Niibori Y, Ageta H, Sekiguchi M, Sugiyama H, Inokuchi K (2009) Adult neurogenesis modulates the hippocampus-dependent period of associative fear memory. Cell 139:814-827. CrossRef Medline
Kleindienst A, McGinn MJ, Harvey HB, Colello RJ, Hamm RJ, Bullock MR (2005) Enhanced hippocampal neurogenesis by intraventricu-

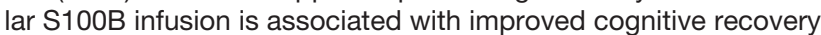
after traumatic brain injury. J Neurotrauma 22:645-655. CrossRef

Kornack DR, Rakic P (1999) Continuation of neurogenesis in the hippocampus of the adult macaque monkey. Proc Natl Acad Sci U S A 96:5768-5773. Medline

Kuhn HG, Dickinson-Anson H, Gage FH (1996) Neurogenesis in the dentate gyrus of the adult rat: age-related decrease of neuronal progenitor proliferation. J Neurosci 16:2027-2033. Medline

Laplante M, Sabatini DM (2012) mTOR signaling in growth control and disease. Cell 149:274-293. CrossRef Medline

Lie DC, Colamarino SA, Song HJ, Désiré L, Mira H, Consiglio A, Lein ES, Jessberger S, Lansford H, Dearie AR, Gage FH (2005) Wnt signalling regulates adult hippocampal neurogenesis. Nature 437: 1370-1375. CrossRef Medline

Lin SP, Chiu FY, Wang Y, Yen ML, Kao SY, Hung SC (2014) RB maintains quiescence and prevents premature senescence through upregulation of DNMT1 in mesenchymal stromal cells. Stem Cell Rep 3:975-986. CrossRef

Lu D, Mahmood A, Qu C, Goussev A, Schallert T, Chopp M (2005) Erythropoietin enhances neurogenesis and restores spatial memory in rats after traumatic brain injury. J Neurotrauma 22:10111017. CrossRef Medline

Lu D, Mahmood A, Zhang R, Copp M (2003) Upregulation of neurogenesis and reduction in functional deficits following administration of DEtA/NONOate, a nitric oxide donor, after traumatic brain injury in rats. J Neurosurg 99:351-361. CrossRef

Magri L, Cambiaghi M, Cominelli M, Alfaro-Cervello C, Cursi M, Pala M, Bulfone A, Garcia-Verdugo JM, Leocani L, Minicucci F, Poliani PL, Galli R (2011) Sustained activation of mTOR pathway in embryonic neural stem cells leads to development of tuberous sclerosis complex-associated lesions. Cell Stem Cell 9:447-462. CrossRef

Marras C, Hincapié CA, Kristman VL, Cancelliere C, Soklaridis S, LI, A, Borg J, Af Geijerstam JL, Cassidy JD (2014) Systematic review of the risk of Parkinson's disease after mild traumatic brain injury: results of the International Collaboration on Mild Traumatic Brain Injury Prognosis. Arch Phys Med Rehabil 95:S238-S244. CrossRef

Mignone JL, Kukekov V, Chiang AS, Steindler D, Enikolopov G (2004) Neural stem and progenitor cells in nestin-GFP transgenic mice. $J$ Comp Neur 469:311-324. CrossRef Medline

Ming GL, Song H (2005) Adult neurogenesis in the mammalian central nervous system. Annu Rev Neurosci 28:223-250. CrossRef Medline

Nikolaeva I, Crowell B, Valenziano J, Meaney D, D'arcangelo G (2015) Beneficial effects of early mTORC1 inhibition after traumatic brain injury. J Neurotrauma

Nottebohm F (2002) Neuronal replacement in adult brain. Brain Res Bull 57:737-749. Medline

Paliouras GN, Hamilton LK, Aumont A, Joppé SE, Barnabé-Heider F, Fernandes KJ (2012) Mammalian target of rapamycin signaling is a key regulator of the transit-amplifying progenitor pool in the adult and aging forebrain. J Neurosci 32:15012-15026. CrossRef Medline

Parent JM, Valentin VV, Lowenstein DH (2002) Prolonged seizures increase proliferating neuroblasts in the adult rat subventricular zone-olfactory bulb pathway. J Neurosci 22:3174-3188. Medline Medline

Parent JM, Yu TW, Leibowitz RT, Geschwind DH, Sloviter RS, Lowenstein DH (1997) Dentate granule cell neurogenesis is increased by seizures and contributes to aberrant network reorganization in the adult rat hippocampus. J Neurosci 17:3727-3738. Medline

Park J, Zhang J, Quu J, Zhu X, Degterev A, Lo EH, Whalen MJ (2012) Combination therapy targeting Akt and mammalian target of rapamycin improves functional outcome after controlled cortical impact in mice. J Cereb Blood Flow Metab 32:330-340. CrossRef

Perry DC, Sturm VE, Peterson MJ, Pieper CF, Bullock T, Boeve BF, Miller BL, Guskiewicz KM, Berger MS, Kramer JH, Welsh-Bohmer 
KA (2015) Association of traumatic brain injury with subsequent neurological and psychiatric disease: a meta-analysis. J Neurosurg 1-16.

Prigatano GP (1987) Recovery and cognitive retraining after craniocerebral trauma. J Learn Disabil 20:603-613. Medline

Ramaswamy S, Goings GE, Soderstrom KE, Szele FG, Kozlowski DA (2005) Cellular proliferation and migration following a controlled cortical impact in the mouse. Brain Res 1053:38-53. CrossRef Medline

Reynolds BA, Weiss S (1992) Generation of neurons and astrocytes from isolated cells of the adult mammalian central nervous system. Science 255:1707-1710. Medline

Rice AC, Khaldi A, Harvey HB, Salman NJ, White F, Fillmore H, Bullock MR (2003) Proliferation and neuronal differentiation of mitotically active cells following traumatic brain injury. Exp Neurol 183:406-417. Medline

Rodgers JT, King KY, Brett JO, Cromie MJ, Charville GW, Maguire KK, Brunson C, Mastey N, Liu L, Tsai CR, Goodell MA, Rando TA (2014) mTORC1 controls the adaptive transition of quiescent stem cells from G0 to G(Alert). Nature 510:393-396. CrossRef Medline

Romine J, Gao X, Xu XM, So KF, Chen J (2015) The proliferation of amplifying neural progenitor cells is impaired in the aging brain and restored by the mTOR pathway activation. Neurobiol Aging 36: 1716-1726. CrossRef Medline

Rozas NS, Redell JB, Hill JL, Mckenna J, 3rd, Moore AN, Gambello MJ, Dash PK (2015) Genetic activation of mTORC1 signaling worsens neurocognitive outcome after traumatic brain injury. $J$ Neurotrauma 32:149-158. CrossRef

Rumman M, Dhawan J, Kassem M (2015) Quiescence in adult stem cells: biological significance and relevance to tissue regeneration. Stem Cells 33:2903-2912. CrossRef

Salmond CH, Sahakian BJ (2005) Cognitive outcome in traumatic brain injury survivors. Curr Opin Crit Care 11:111-116. Medline

Sato M, Chang E, Igarashi T, Noble LJ (2001) Neuronal injury and loss after traumatic brain injury: time course and regional variability. Brain Res 917:45-54. Medline

Schmidt RH, Scholten KJ, Maughan PH (1999) Time course for recovery of water maze performance and central cholinergic innervation after fluid percussion injury. J Neurotrauma 16:11391147. CrossRef Medline

Seaberg RM, van der Kooy D (2002) Adult rodent neurogenic regions: the ventricular subependyma contains neural stem cells, but the dentate gyrus contains restricted progenitors. J Neurosci 22: $1784-1793$

Seri B, García-Verdugo JM (2001) Astrocytes give rise to new neurons in the adult mammalian hippocampus. The $\mathrm{J}$ Neurosci 21: 7153-7160. Medline

Shapiro LA, Ribak CE (2005) Integration of newly born dentate granule cells into adult brains: hypotheses based on normal and epileptic rodents. Brain Res Brain Res Rev 48:43-56. CrossRef Medline

Shors TJ, Miesegaes G, Beylin A, Zhao M, Rydel T, Gould E (2001) Neurogenesis in the adult is involved in the formation of trace memories. Nature 410:372-376. CrossRef Medline

Sierra A, Martín-Suárez S, Valcárcel-Martín R, Pascual-Brazo J, Aelvoet SA, Abiega O, Deudero JJ, Brewster AL, Bernales I, Anderson AE, Baekelandt V, Maleti-Savati M, Encinas JM (2015) Neuronal hyperactivity accelerates depletion of neural stem cells and impairs hippocampal neurogenesis. Cell Stem Cell 16:488503. CrossRef
Sivanandam TM, Thakur MK (2012) Traumatic brain injury: a risk factor for Alzheimer's disease. Neurosci Biobehav Rev 36:13761381. CrossRef Medline

Spencer SL, Cappell SD, Tsai FC, Overton KW, Wang CL, Meyer T (2013) The proliferation-quiescence decision is controlled by a bifurcation in CDK2 activity at mitotic exit. Cell 155:369-383. CrossRef Medline

Sun D, Colello RJ, Daugherty WP, Kwon TH, McGinn MJ, Harvey HB, Bullock MR (2005) Cell proliferation and neuronal differentiation in the dentate gyrus in juvenile and adult rats following traumatic brain injury. J Neurotrauma 22:95-105. CrossRef Medline

Sun D, Daniels TE, Rolfe A, Waters M, Hamm R (2015) Inhibition of injury-induced cell proliferation in the dentate gyrus of the hippocampus impairs spontaneous cognitive recovery after traumatic brain injury. J Neurotrauma 32:495-505. CrossRef

Sun D, McGinn MJ, Zhou Z, Harvey HB, Bullock MR, Colello RJ (2007) Anatomical integration of newly generated dentate granule neurons following traumatic brain injury in adult rats and its association to cognitive recovery. Exp Neurol 204:264-272. CrossRef

Van Praag H, Schinder AF, Christie BR, Toni N, Palmer TD, Gage FH (2002) Functional neurogenesis in the adult hippocampus. Nature 415:1030-1034. CrossRef Medline

Villasana LE, Kim KN, Westbrook GL, Schnell E (2015) Functional integration of adult-born hippocampal neurons after traumatic brain injury. eNeuro 2. CrossRef . Advance online publication. doi:10.1523/ENEURO.0056-15.2015

Wang X, Gao X, Michalski S, Zhao S, Chen J (2016) Traumatic brain injury severity affects neurogenesis in adult mouse hippocampus. J Neurotrauma 33:721-733.

Wu H, Lu D, Jiang H, Xiong Y, Qu C, Li B, Mahmood A, Zhou D, Chopp M (2008) Simvastatin-mediated upregulation of VEGF and BDNF, activation of the PI3K/Akt pathway, and increase of neurogenesis are associated with therapeutic improvement after traumatic brain injury. J Neurotrauma 25:130-139. CrossRef

Yagita Y, Kitagawa K, Ohtsuki T, Takasawa K, Miyata T, Okano H, Hori M, Matsumoto M (2001) Neurogenesis by progenitor cells in the ischemic adult rat hippocampus. Stroke 32:1890-1896.

Yamashita T, Ninomiya M, Hernandez Acosta P, Garcia-Verdugo JM, Sunabori T, Sakaguchi M, Adachi K, Kojima T, Hirota Y, Kawase T, Araki N, Abe K, Okano H, Sawamoto K (2006) Subventricular zone-derived neuroblasts migrate and differentiate into mature neurons in the post-stroke adult striatum. J Neurosci 26:66276636. CrossRef

Zhao C, Teng EM, Summers RG, JR, Ming GL, Gage FH (2006) Distinct morphological stages of dentate granule neuron maturation in the adult mouse hippocampus. J Neurosci 26:3-11. CrossRef Medline

Zheng W, Zhuge Q, Zhong M, Chen G, Shao B, Wang H, Mao X, Xie L, Jin K (2013) Neurogenesis in adult human brain after traumatic brain injury. J Neurotrauma 30:1872-1880. CrossRef Medline

Zhou H, Chen L, Gao X, Luo B, Chen J (2012) Moderate traumatic brain injury triggers rapid necrotic death of immature neurons in the hippocampus. J Neuropathol Exp Neurol 71:348-359. CrossRef Medline

Zhu X, Park J, Golinski J, Qiu J, Khuman J, Lee CC, Lo EH, Degterev A, Whalen MJ (2014) Role of Akt and mammalian target of rapamycin in functional outcome after concussive brain injury in mice. J Cereb Blood Flow Metab 34:1531-1539. CrossRef Medline 